\title{
A sociedade ovimbundu nos relatórios de viagens do húngaro László Magyar: sul de Angola, meados do século XIX
}

The ovimbundu society in the travel narratives of the Hungarian László Magyar: southAngola, mid Ninetenth century

La sociedad ovimbundu en los relatos de viagen del hungaro László Magyar:

sur de Angola, medio siglo XIX

Éva Sebestyén

\section{Resumo}

Entre os vários viajantes que visitaram Angola em meados de século XIX, há um explorador húngaro, László Magyar, cuja vida e trabalho têm sido pouco estudados fora da Hungria. É um anti-herói, que não se deixou influenciar por instituições que acenavam com reconhecimento científico internacional e recompensas. Seguiu seu caminho de explorador solitário, e nos seus trabalhos aborda assuntos relevantes à época (escravidão doméstica, viagem de caravana a longa distância, comércio interno, descrição de sociedades ovimbundu comparada à vida seminômade de pastores). Este estudo debruça-se sobre a trajetória de vida de um homem com visão pecu- liar tendo a coragem de traçar um percurso de vida independente misturada a seu gosto pela aventura e exploração científica.

Palavras-chave: Ovimbundu. Viagem a longa distância. Explorador húngaro.
$\mathrm{PhD}$ em Antropologia. Investigadora Centro de Estudos Africanos da Universidade do Porto. E-mail: sebestyen99@gmail.com.

Recebido em 17/11/2014 - Aprovado em 25/03/2015 http://dx.doi.org/10.5335/hdtv.15n.1.5278 
Em meados de século XIX, entre os viajantes estrangeiros que visitaram Angola, há um explorador húngaro, László Magyar, cuja vida e trabalho têm sido pouco estudados fora da Hungria. A sua obra é pouco conhecida devido ao fato de seus textos terem sido publicados em húngaro, e na Hungria, e, também, por ele não ter aceitado nenhum trabalho em instituições portuguesas e inglesas. É um anti-herói, que não se deixou influenciar por instituições que acenavam com reconhecimento científico internacional e recompensas. Seguiu seu caminho de explorador solitário apoiado, inicialmente, pelo seu sogro, o potentado ovimbundu ${ }^{1}$ do reino de Bié, mas com a morte deste ficara dependendo de si mesmo. Em seus trabalhos, com um bom senso refinado, aborda assuntos relevantes à época (escravidão doméstica, viagem de caravana a longa distância, comércio interno, descrição de sociedades ovimbundu comparada à vida seminômade de pastores). Apesar de essas temáticas serem de interesse do governo colonial português, Magyar destinou sua obra ao público húngaro, convidando-o a conhecer o seu cotidiano africano. Em seus textos, há uma mensagem codificada destinada ao seu público, sugerindo seguir o seu caminho, já melhor preparado, e estabelecer empresas em áreas não exploradas, como a exploração de recursos naturais. A relevância da obra do Magyar para os interessados brasileiros encontra-se não só na presença de comerciantes brasileiros no Sul de Angola, Benguela, Mossamedes, mas também, no fato de dar a conhecer uma cultura africana com reminiscências no Brasil contemporâneo.

\section{0 percurso de vida de Ladislau Magyar}

Magyar nasceu em 13 de novembro de 1818, na cidade Szombathely, na Hungria. As circunstâncias do seu nascimento foram decisivas para o resto da sua vida. Sendo filho ilegítimo de um excelente agrônomo húngaro de origem nobre, Imre Magyar, no batismo foi registrado com o nome László (Ladislau em português) Horváth, recebendo o sobrenome da mãe falecida três semanas depois do parto. Ladislau Magyar não chegou a ser legalmente reconhecido pelo pai, mas, por um provável consentimento informal, o pai o autorizou a usar o seu sobrenome, que o explorador adotou depois de ter deixado para sempre o continente europeu. Ele próprio nunca escreveu sobre sua vida passada na Hungria e começou sua biografia a partir da saída do porto de Trieste em um barco de correio, Pacchetto de Trieste, rumo ao Brasil.

A reconstrução da vida de Ladislau é um trabalho de investigação até mais difícil do que o estudo da sua obra. O que se sabe é que estudou em um dos melhores estabelecimentos do ensino da época, no colégio dos Padres Pios, em várias localidades na Hungria: Kalocsa, Pest, Baja e Szabadka. Nos livros de matrícula, foi registrado pelo nome de nascimento, László Horváth, mas o pai aparecia como seu tutor. Depois dos estudos secundários, trabalhou como escrivão junto ao pai, que era gestor das propriedades da família Orczy, em Jankovácz. Segundo seus biógrafos ele desistiu da carreira de administrador de propriedades agrícolas e optou pelos estudos náuticos em Fiume (hoje Rijeka). Apesar das várias pesquisas realiza- 
das no arquivo estadual de Rijeka, eu nunca consegui encontrar seu nome entre os alunos da escola náutica, nem sua estadia em Fiume. Esses aspectos essenciais para entender a sua futura vida de explorador foram recentemente observados por József Horváth, capitão húngaro de barco fluvial, em sua pesquisa sobre a história da marinha húngara em Fiume, outrora o único porto marítimo húngaro, ao lado do Trieste (porto austríaco). O Sr. Horváth encontrou o atalho da pesquisa, pois, ao invés de provar a estadia de Ladislau em instituições (escola náutica, autorização de estadia, solicitação de passaporte, etc.), opção que adotou e analisou foi a lista dos tripulantes dos barcos nos quais Ladislau pôde realizar sua aprendizagem e experiência de marinheiro. Foi assim que ele encontrou o barco Contessa Almássy e o cadete László Horváth registrado na lista dos tripulantes.

Pela saída e regresso do barco e por um anúncio de jornal húngaro da capital, também localizado pelo capitão Horváth, já podemos confirmar que Magyar estudou na escola náutica, teve experiência de marinheiro no Mediterrâneo antes de relizar sua grande viagem, desde Trieste, passando, em seguida, pela Bahia de Todos os Santos e seguiu ao Rio de Janeiro, onde se empregou como marinheiro num barco negreiro espanhol com destino à baia da Guiné. Carregado de escravos, aportou em Cuba. Arrependeu-se de participar no tráfico negreiro como marinheiro e ao regressar à Havana utilizou todo o seu salário para aperfeiçoar seus estudos náuticos com um especialista, possivelmente na Escola Náutica de Regla. Depois de se dedicar meio ano aos estudos, partiu no barco espanhol Albatross, que ganhou fama pela participação nas lutas de independência lideradas por Símon Bolívar.

Em seu périplo, viajou por partes das Índias orientais (na atual Indonésia), Madagascar, Cabo da Boa Esperança e Rio de Janeiro. No Rio, foi hospedado na casa de um rico comerciante de origem húngara, José Vámosi, um verdadeiro mecenas durante sua estadia latino-americana. Vámosi, por ter casado com uma parenta do líder argentino Manuel Rosas, forneceu a Magyar uma carta de apresentação a fim de o empregar como oficial da marinha argentina. Magyar foi aprovado no exame e contratado como tenente da marinha. Imediatamente foi posto no combate contra o Uruguai, no bloqueio de Montevidéu, em 1845. A frota argentina perdeu o combate e Magyar chegou a ser prisioneiro de guerra em Maldonado, onde tivera as primeiras ideias de exploração científica.

Em 1846, pediu apoio à Academia de Ciências da Hungria para realizar duas expedições. Uma viagem a partir de Maldonado com destino ao Rio de Janeiro, passando por Uruguai, Paraguai, Argentina, Bolívia e Peru, com o objetivo de estudar a topografia do Paraguai para a confecção de um mapa, de observar costumes indígenas e minas de prata e ouro na Bolívia, findando a viagem em Cuzco. A segunda expedição partiria do Rio de Janeiro rumo a Minas Gerais, a fim de analisar metais preciosos em Ouro Preto, mas também para fazer uma coleção, para o Museu Nacional da Hungria, da flora e fauna de Mato Grosso, mapear o percurso do rio Paraguai, continuando sua viagem pela Bolívia ao Peru, para estudar o percurso do 
rio Amazonas, e finalizar a jornada nas montanhas altas da costa Pacífica. Regressaria à Hungria com a coleção para o Museu Nacional e com mapas sobre as regiões visitadas.

Essa proposta se encontra no Arquivo da Academia, mas observa-se que a direção da instituição decidiu não apoiá-la devido aos altos custos e, também, por não conhecer o proponente. Sem ter a resposta, Magyar seguiu ao Rio de Janeiro e daí a Calabar Novo (na atual Nigéria), onde se empregou como comandante da frota de um sultão. Apesar de estar contente com seu novo trabalho, por razões de saúde mudou-se para Angola, iniciando, em 1848, a exploração do rio Congo (Zaire) e de pontos de tráfico clandestino de escravos. Das águas do rio Congo, via Luanda, foi à Benguela em dezembro de 1848. O plano de mudança profissional, iniciado na América Latina, começava a se realizar. Baseado em informações recolhidas a moradores benguelenses (predominantemente portugueses e brasileiros) experimentou um percurso pessoal para poder realizar as suas explorações. Optou pela vida de sertanejo, isto é, comerciante itinerante no interior do país que adquire produtos africanos com mercadorias europeias. Esse modo de vida permitiu-lhe movimentar-se a longa distância em caravanas ${ }^{2}$ e conhecer vários lugares geográficos e povos, objetos do seu trabalho de exploração científica. Assim deve ter realizado os seus primeiros contatos com a casa comercial do português Manuel Antonio Teixeira Barbosa, um rico comerciante, com sede em Benguela e Lisboa. As suas futuras e frequentes idas a Benguela devem-se, em parte, à comercialização de produtos africanos, sobretudo marfim e cera, e mais tarde urzela, junto a essa casa comercial, e a aquisição de produtos europeus (aguardente, tecidos, pólvora, armas, etc.) para suas viagens no interior. Passando apenas um mês em Benguela junta-se a uma grande caravana de bienos_(naturais do Bié) em janeiro de 1849 e resolve definitivamente estabelecer-se no Bié. O potentado do Bié oferece-lhe uma das filhas acompanhada de um grande número de escravos a serviço dela, casam-se, então, no mês de maio de 1849. Com esse laço familiar e com a proteção do sogro, conseguiu acesso a outros reinos angolanos, sobretudo no Sul de Angola. Teve filhos, e o primogênito chamava-se Artur Magyar (o seu nome africano foi Sah-Quilembe Gonga). Magyar considerou-o como seu herdeiro, cujo destino seria estudar engenharia de minas na Hungria e retornar a Angola, dando continuidade a laços entre a família da Hungria e a de Angola nas futuras gerações, e também em empreendimentos de exploração.

No regresso das suas primeiras viagens de 1851 a 1853, teve informaçoes sobre a chegada, em Benguela, de uma caravana de mouros de Zanzibar. Sob o efeito desse desafio, surge o anúncio do governador de Benguela procurando interessados em realizar a viagem de contra-costa, isto é, partir de Angola a Moçambique e regressar a Angola, mas satisfazendo as instruções precisas do governador durante a viagem. Ladislau candidatou-se a essa proposta e foi aprovado pelo Conselho Ultramarino, em Lisboa. A Academia de Ciências da Hungria, por meio de um geógrafo interessado nas explorações de Ladislau Magyar, entra em contato com ele, publica, em forma de livro, todos os relatórios de viagem já publicados pelos 
jornais da capital húngara, e mais o último sobre o Congo.

Magyar, estimulado pelo interesse acadêmico húngaro sobre suas explorações, o que era o sonho da sua vida, vai adiando sua colaboração com as instituições portuguesas e inglesas, e envia o manuscrito do seu primeiro livro propriamente dito ao seu pai, que o entrega à Academia de Ciências da Hungria. Os acadêmicos recebem calorosamente o manuscrito e, depois de uma consulta positiva, foi decidida a sua edição. Mais do que isso, no dia 21 de dezembro de 1857, e ainda antes da sua publicação (fevereiro de 1859), Magyar foi eleito como membro correspondente da Academia de Ciências da Hungria.

Porém, a vida de Magyar em Angola tomou novo curso. Mataram seu sogro, perdeu suas propriedades e teve que fugir e começar uma nova vida, basicamente nômade, de coletor de urzela ao longo da costa atlântica entre Benguela e Mossamedes. Entre o envio do manuscrito do livro e a reação da Academia, decorreu-se um ano e meio de desespero. Na altura da correspondência retomada, esgotaram-se suas energias para novas explorações. Essa luta por sobrevivência já não permitia realizar grandes viagens de longa distância que exigiam recursos financeiros. A sua força de criação desvaneceu, e a malária crônica tirou a sua vida no dia 9 de novembro de 1864, numa aldeia de pescadores, Ponta do Cuio do Conselho de Dombe Grande, perto de Benguela. Deixou um órfão, o seu primogênito, cujo destino é desconhecido. A Academia de Ciências da Hungria, só quatro anos depois da morte de Magyar, começou a interessar-se por seu pa- radeiro. Sabedores da notícia da morte, recebida no mesmo ano de 1868, solicitou-se ao governo português para localizar e entregar a sua herança literária. Só em 1873 a Academia recebeu a resposta definitiva sobre o incêndio que destruiu todos os manuscritos deixados por Ladislau Magyar.

\section{0 contexto histórico do livro As viagens de Ladislau Magyar ao interior da África Austral}

Esse livro apresenta uma gênese bem complexa. O ponto de partida foi o acaso do aparecimento de uma pequena caravana de mouros de Zanzibar, nas margens do rio Zambezi, em 1851, que seguiu viagem para Benguela, aonde chegou em $1852^{3}$. A travessia do continente tratava-se de um plano antigo português, que remonta ao século XVIII, sugerido pelo geógrafo francês Jean Baptiste Bourguignon D'Anville, que Sá da Bandeira relançou em $1844^{4}$, mas só chegou a ser realizado com financiamento do governo metropolitano português em 1877.

Assim, a travessia feita por mouros causou um verdadeiro choque no governo português, tanto na capital colonial, Luanda, como em Benguela, aonde chegaram os mouros. Ferido no orgulho patriótico, em 1853, o governador de Benguela lançou um anúncio no Boletim Oficial do Governo Geral de Angola, convocando homens experientes e de cabedal a realizar a travessia da costa atlântica à costa índica, mas arcando com os custos e seguindo as instruções do governo. Sem candidatos, o mesmo governador dirigiu-se a Antonio Francisco Silva Porto 5 . O sertanejo de Bié, com muitos anos de experiência em viagens pelo interior de 
Angola, aceitou o honroso convite. Partiu, mas adoeceu numa fase avançada da viagem e abandonou a travessia, que foi executada pelos seus escravos. O governo, alegando a sua ausência na parte final, não reconheceu a realização da travessia. Entretanto, Ladislau Magyar, depois de ter regressado da sua viagem de Kwanyama, passou por Gambos. Informado sobre o anúncio do governador de Benguela, dirigiu-lhe uma carta ${ }^{6}$ contendo os relatórios das suas viagens anteriores, o seu conhecimento sobre a chegada dos mouros de Zanzibar ${ }^{7}$ e sua proposta para indicar o caminho mais curto da travessia. Com tais informações, completaria suas viagens, realizar-se-iam uma publicação e a elaboração de um mapa de Angola. Curiosamente, um mês antes da chegada dos mouros, perto da sua estadia em Lunda, Magyar escrevera uma carta ao seu pai, na Hungria, na qual abordava a ideia da travessia do continente africano e solicitava apoio de um mecenas húngaro, para que os húngaros ganhassem fama com a façanha. ${ }^{8}$

A proposta de Magyar ao governador de Benguela gerou um longo processo administrativo entre o governo de Benguela, $o$ governo geral de Angola e o Ministério da Marinha e Ultramar, esse último por meio do Conselho Ultramarino, que tomou decisão positiva sobre a matéria em 24 de janeiro de 1854. Definiram-se as benesses (cargo de tenente coronel, pagamento vitalício) e os requisitos (provas demonstradas perante peritos sobre a sua capacidade de medição e feitura de mapa) para a empreitada. Porém, na decisão do Conselho Ultramarino, o objetivo inicial do anúncio do governador de Benguela, a travessa continental, um dos itens da proposta do Magyar, não foi considerado. Parece que houve uma mudança nos objetivos do governo colonial e o fulcro da decisão passou a ser a confecção do mapa de Angola. A travessia até a contra costa foi posta ao lado e a futura ideia do mapa cor de rosa, ou seja, juntar Angola a Moçambique, não se efetivou. Há dois dados que confirmam essa preferência. Um era o exame do conhecimento cartográfico do Magyar perante peritos em engenharia militar em serviço ao governo português em Angola. O outro era o trabalho de levantamento cartográfico de Angola que, possivelmente, já tinha iniciado ou estava para ser iniciado pelos engenheiros militares, cujo resultado foi publicado em 1863, quatro anos depois da publicação do manuscrito mapa de Magyar, como anexo de seu livro. Não se pode excluir a hipótese de que o mapa de Magyar chegou ao conhecimento das autoridades portuguesas, já que o manuscrito, junto com mapa, foi enviado, pela via oficial, do governo de Benguela ao governo geral de Angola e ao Ministério da Marinha e Ultramar. De qualquer modo, o próprio Sá da Bandeira continuava a manter o seu interesse sobre uma futura colaboração com Magyar. A sua política visava a exploração econômica precedida pela efetiva ocupação militar de Angola. Assim, era urgente ter um mapa sobre Angola em sua totalidade e não só para a faixa costeira utilizada na perseguição a navios negreiros.

Paralelamente aos trâmites e interesses portugueses em Angola, a Real Sociedade de Geografia de Londres também demonstrou interesse pelas explorações do viajante húngaro. Por sua vez, da Academia de Ciências da Hungria chegaram as primeiras cartas so- 
licitando a preparação de um manuscrito sobre as viagens para fins de publicação. Desse modo, Magyar encontrou-se entre a cruz e a espada: optar por um caminho de fama e de financiamento das suas futuras explorações, propostas pelos portugueses e ingleses, ou um caminho duvidoso de glória e de conforto sugeridos por seus compatriotas. A força-motriz da sua vida, ser reconhecido pelo pai e pelo seu país, determinou a escolha, congelando os objetivos portugueses e ingleses.

Magyar preparava o seu regresso à Hungria e esperava reconhecimento - tal como o desfrutado por David Livingstone ${ }^{9}$ -, com a publicação da sua primeira obra, cuja confecção levou dois anos. Os arquivos preservam bem o caminho do manuscrito desde Benguela até a Academia de Ciências da Hungria, entre 14 de outubro e 5 de dezembro de 1857. Magyar entregou o manuscrito pessoalmente ao governador de Benguela, que o mandou ao governador geral de Angola. Esse solicitou ao Ministério da Marinha e Ultramar o envio do manuscrito, por via diplomática, ao seu destinatário na Hungria. Assim, o Ministério da Marinha entregou ao Ministério dos Negócios Estrangeiros, em 16 de outubro de $1857^{10}$, e esse ao embaixador de Áustria em Lisboa, que remeteu ao Ministério dos Negócios Estrangeiros do Império austro-húngaro, que reportou, em 29 de novembro de 1857, ao Governo do Reino da Hungria, e esse, enfim, à Academia de Ciências da Hungria, em 5 de dezembro de 1857. O recebimento do manuscrito havia sido reconfirmado ao governador geral de Angola, José Rodrigues Coelho do Amaral, anterior governador de Benguela, em 31 de julho de $1857^{11}$.
Depois da chegada do manuscrito na Academia de Ciências da Hungria, tudo se acelerou em torno do destino da preciosa obra. No dia 7 de dezembro, apenas dois dias depois da sua recepção, a Comissão da História apresentou o manuscrito aos acadêmicos e, no dia 10 de dezembro, empenhou dois acadêmicos para elaborar um relatório científico sobre o manuscrito. Apenas duas semanas passaram ${ }^{12}$ e os dois peritos incumbidos, o filólogo Ferenc Toldy, e o secretário geral da Academia e explorador da Sibéria, Antal Reguly, deram parecer positivo e julgaram o manuscrito digno de publicação. $\mathrm{O}$ geógrafo János Hunfalvy, já com conhecimento dos trabalhos anteriores de Magyar, foi incumbido de fazer a edição da obra. Fora ele quem se encarregou da publicação do primeiro livro de Ladislau ${ }^{13}$, uma coletânea de curtos relatos de suas viagens e cartas familiares. Bilíngue e membro de uma minoria de origem alemã no Norte da Hungria, realizou o trabalho em curtíssimo prazo, pois recebera o manuscrito em dezembro de 1857 e terminou o tratamento científico, em húngaro, em fevereiro de 1859, e a versão alemã no verão.

A edição húngara fazia parte da troca nacional de instituições de ensino e das academias internacionais, chegando, assim, a todas as capitais principais à Europa e até aos Estados Unidos, e, talvez, ao Brasil. Mas, graças à tradução alemã, é que o trabalho de Magyar ficou conhecido e passou a integrar citações de historiadores sobre Angola.

$\mathrm{O}$ editor alterou a linguagem bem peculiar e saborosa do manuscrito de Magyar, que criou uma linguagem digna de Grande Sertão Veredas, de Guimarães Rosa. Magyar 
usou um húngaro inexistente em seu país, um idioma recriado por alguém que vivia há muito tempo fora do seu país. Colocou novas palavras no lugar das esquecidas, o que enriquecia o texto com o vocabulário adquirido durante a sua vida. Essa alegre interferência linguística vinha do tempo da escola com latim, alemão e italiano, mas continuou com o seu convívio com português do Brasil e de Angola, sem mencionar as línguas africanas, sobretudo umbundu, que aprendeu em sua convivência com povos "ovimbundu", inclusive em sua própria casa. O manuscrito tem uma linguagem vigorosa, dinâmica, transmite uma força de viver, que muitas vezes, foi atenuada ou modificada na edição. Mas a força da expressão, mesmo com cortes, não desapareceu.

Porém, depois de Magyar ter mandado o seu manuscrito, seguiu-se um período de impasse que durou anos. Após editar o primeiro tomo, a Academia esperava os próximos dois tomos, mas Magyar queria ter notícias sobre a recepção do livro como condição para seguir a elaboração dos outros dois. $\mathrm{O}$ entusiasmo e a total confiança depositados na edição húngara, como chave do seu futuro e o catalisador ao seu regresso à Hungria, falharam. Nem a Academia tinha condições de financiar a sua viagem à pátria, nem o pai concordava em desistir da colaboração do governo português. Magyar sentiu seu sonho e sua força de criação desvanecerem.

\section{Apresentação do livro}

Magyar sintetiza o objetivo da sua exploração angolana com base na investigação sobre a geografia, a hidrologia, os dados et- nográficos e estatísticos dos povos com os quais se deparou, sobretudo os ovimbundu do Sul de Angola. Destaca a importância do conhecimento das línguas locais, do convívio e da adaptação ao modo de viver dos povos visitados.

O livro deixa entrever uma grande empatia do autor para com os seus companheiros de viagem e os transtornos da vida em caravana. Trata igualmente bem os homens livres ao seu serviço, os carregadores, os seus escravos e as eminências do alto estrato social. Ele próprio, adotando um modo de vida africano de morador e empreendedor, adaptou-se naturalmente às dificuldades surgidas e às reações africanas em determinadas situações.

\section{A composição do livro}

O livro se divide em dez capítulos seguidos de pequenos estudos relacionados à língua umbundu, à navegabilidade dos rios e à preparação para a próxima viagem de caravana.

O primeiro capítulo, depois de ter apresentado os edifícios mais importantes de Benguela (palácio do governador, igreja, hospital de Misericórdia, cemitérios separados para população "branca" e africana), relata o modo de viver da população civilizada, de origem predominantemente européia, portuguesa e brasileira, e seus filhos mulatos. Muitos deles tinham casas comerciais pelas quais faziam o comércio de longa distância com o interior de Angola, por meio de seus representantes, ou mesmo diretamente com os comerciantes africanos (caso bieno). Geralmente, essas casas comerciais 
eram filiais de seus países de origem, Portugal ou Brasil. Magyar chamou atenção sobre o efeito causado pela proibição do tráfico atlântico de escravos, ou seja, para a queda no outrora florescente tráfico de cativos e o crescimento do comércio de marfim, cera e urzela. Aborda a questão da divisão do trabalho, na qual só cabe ao escravo desempenhar o papel de artesão, mas não as atividades de maior prestígio como a de caçador de elefante ou a de ferreiro, ou por serem certas atividades tradicionalmente desempenhadas pela mulher, como a olaria. Magyar relata a estrutura dos participantes da caravana, a contratação de trabalhadores, ou a compra (no caso de escravos), os salários, as obrigações, os deveres e direitos dos contratados, a lista das mercadorias e seus valores, a embalagem e o salário dos carregadores conforme o valor e o peso da carga.

O segundo capítulo analisa a partida de Benguela a Bié, no qual continua a descrição dos novos membros contratados da caravana, versa sobre o início da viagem entre Benguela e o reino Kissanje (Quissanje com a ortografia portuguesa).

O terceiro capítulo prossegue com o diário até o reino Kiaka, repleto de relatos etnográficos sobre a colheita de mel, inclusive a menção ao pássaro de mel, a caça de pacaça, a prova de veneno; e o papel de feiticeiro, que, além de curar, adivinhar, pôr e tirar feitiço, também era juiz em julgamentos tradicionais. No quarto capítulo, são narrados os acontecimentos até o reino Huambo, relacionados à viagem da caravana, o pagamento habitual dos carregadores, a vanguarda da proteção e o pagamento da taxa de passagem.
A última etapa da caravana até Bié está apresentada no quinto capítulo. Magyar foi visitado por um ex-escravo de um mineiro brasileiro que queria lhe mostrar minas de ouro abandonadas, mas ele opta por seguir a viagem de caravana e alcançar o objetivo de estabelecer-se em Bié: garimpar ouro. Descreve, detalhadamente, o ritual do reencontro dos familiares depois da chegada ao Bié e a viagem feita por um dos carregadores.

O sexto capítulo dedica-se ao seu estabelecimento, ao sistema da contratação dos escravos domésticos e ao casamento com a filha do potentado do Bié; também inicia o seu estudo monográfico sobre Bié, com dados geográficos e estatísticos. Por sua vez, $\mathrm{o}$ sétimo capítulo prosegue com a monografia sobre o Reino do Bié. Trata do mito da fundação do reino, da organização administrativa, da política, do sistema de defesa, da vida econômica, do comércio baseado na troca de mercadorias, do sistema de parentesco, das festas de colheita, da caça. Retoma o tema do escravo doméstico, das estratégias cativas para melhorar a vida, seja por fuga, seja por casamento com mulher livre. Volta a abordar a questão da divisão de trabalho relacionada ao prestígio das tarefas, de forma que tarefas como a caça, a pesca e o comércio de longa distância são consideradas atividades masculinas e as demais ocupações pertencentes à alçada feminina ou, caso houvesse, restaria aos escravos da família. O oitavo capítulo continua a abordar a monografia do reino de Bié, descrevendo o estreito entrelaçamento entre os sistemas legal e religioso ovimbundu, descreve as principais atividades artesanais e a formação dos aprendizes. Contém uma subunidade com 
as características físicas e mentais dos ovimbundu, tangenciando sobre o tema do corpo e da saúde e dos rituais da morte.

O nono capítulo é uma apresentação de dados geográficos e demográficos de todos os reinos ovimbundu, com observações e sugestões ao governo colonial português sobre como remediar erros cometidos e aplicar novas medidas em prol do desenvolvimento.

Os três estudos anexos do Magyar não contêm enumeração. O primeiro é uma sucinta apresentação da gramática umbundu, mas enriquecida com um vocabulário da vida quotidiana, provérbios e diálogos reproduzidos. O segundo estudo trata da navegabilidade dos rios em que aconselha construir pequenos trechos ferroviários para cobrir maior terreno do interior, o que facilitaria a conquista militar portuguesa e a civilização dos povos do interior de Angola. O último anexo apresenta sua experiência pessoal sobre como organizar uma caravana, e retoma um destino marcado por hostilizações. Por fim, o livro é acompanhado por oito desenhos e um mapa do Sul de Angola.

\section{Os principais temas do livro}

As questões principais apresentadas no livro referem-se ao mapeamento do meio físico (geográfico, hidrológico, flora, fauna, recursos naturais), à etnografia dos povos visitados -, destacando o sistema de poder, de parentesco -, à aquisição de recursos, à produção, ao comércio, à divisão sexual do trabalho e ao exercício de direito consuetudinário ligado à religião. Também se sobressaem assuntos relacionados a uma melhor gestão colonial, sobretudo de interesse do governo colonial português em informações sobre tráfico ilegal de cativos e escravidão doméstica, mas sem deixar de lado o comércio interno e seu melhoramento por meio da rede hidrográfica do país.

Os temas adicionais deste quadro geral referem-se a um campo pouco estudado pelos europeus, como, a adaptação dos africanos ao calor, ao frio, ao peso, a longas noitadas de festas seguidas de trabalho no início do dia, a aptidão a percorrer grandes distâncias, situações humanas extremas. Magyar escreve, com admiração, sobre a excelente capacidade mental, seja na orientação, no registro de dados ou na resolução de fatos inesperados. De outra forma, um dos temas ainda subjacentes é o abuso do poder social expresso pelos potentados perante os súditos, do marido em relação à mulher, do feiticeiro diante de toda a escala social dos ovimbundu. Doravante, abordaremos um tema de maior interesse, nomeadamente o escravo doméstico.

O mérito do estudo de Magyar sobre a escravatura, inclusive o levantamento de dados, é que ele associou o estado da escravidão à relação laboral dos serviçais. Essa visão, possivelmente única em sua época, reapareceu, na segunda metade do século XX, entre historiadores especialistas no estudo do tráfico transatlântico de cativos. ${ }^{14}$

Assim, de certa forma, Magyar antecede a Claude Meillassoux ${ }^{15}$, pois aludiu ao cativo como mercadoria, cuja compra e venda nos mercados do interior apresentavam um continuum com os trabalhos domésticos. Assim, outra grande contribuição do Magyar, e também a de seu contemporâneo Silva 
Porto, foi a apresentação de atividades mais diversificadas desempenhas pelos escravos nas sociedades ovimbundu. Além dos trabalhos conhecidos de lavrador, artesão, etc., havia escravos incumbidos de representar seus senhores no comércio de longa distância, conduzindo mercadoria europeia de grandes valores e adquirindo, por meio delas, produtos locais para exportação como marfim, cera e, sobretudo, escravos.

A posição pioneira de Ladislau Magyar ilumina questões conhecidas, mas mal estudadas, sobre exploração do trabalho e sobre a situação social de mulher livre, igualada ao escravo doméstico. Com efeito, de certo modo, sua abordagem reflete sua própria experiência húngara no trabalho de escrivão, ao lado do seu pai gestor, numa das fazendas de um aristocrata húngaro aberto ao desenvolvimento da produção e às condições humanas dos seus serviçais.

Chama-lhe atenção, porém, o 'novo' uso do escravo como mão de obra gratuita no transporte de mercadorias, o que gerava duplo lucro, pois os escravos também eram vendidos depois da entrega das cargas. Pode ser que Magyar tivesse uma visão idílica dos povos com os quais conviveu, mas ele condenou a escravidão como sistema, principalmente o tráfico transatlântico. Por ter trabalhado como marinheiro num barco negreiro, levantou suspeita sobre seu envolvimento no tráfico de cativos, bem como por ter vivido em regiões infestadas com embarcações ilegais. Assim, alguns investigadores contemporâneos a Magyar, e mesmo alguns do século $\mathrm{XXI}^{16}$, achavam que ele era traficante de escravos. Porém, ele, como Silva Porto, dentre outros comerciantes do inte- rior, tinham os seus escravos domésticos, como o tinham todos os habitantes livres (os comerciantes, fazendeiros, potentados, estrangeiros), pois era a única mão de obra disponível. Mas, contrariamente a outros negociantes, nunca houve acusação e nem processo jurídico contra ele, o que confirmaria seu envolvimento no tráfico clandestino de cativos. Ao contrário, seus relatos de viagem descrevem os cativos com muita simpatia, reconhecendo o seu trabalho, a fidelidade e a persistência em ficar com ele. Na verdade, foram seus escravos os seus verdadeiros companheiros de viagem, os executores dos trabalhos de subsistência. Ele compartilhou sua vida diária com eles, ensinando, por exemplo, português, até a última hora de sua vida. Em suas correspondências com vizinhos, preocupava-se com o bem-estar, solicitando comida e bebida para sustentá-los.

Qualquer que tenha sido o julgamento de Magyar sobre tráfico e escravidão ${ }^{17}$, juntando suas dispersas descrições sobre os vários tipos de escravidão, pode-se reunir dados preciosos sobre os caminhos de se tornar escravo, sua tipologia, suas estratégias em melhorar de vida e até de alcançar a liberdade. Todavia, no geral, Magyar distingue dois tipos básicos de escravo: o escravo de estado temporário, ou escravo de penhor, que é o hafuka, e o escravo propriamente dito, o pika ou dongo.

O hafuka, o escravo de penhor, é o homem livre de nascimento tornado cativo por penhor, mas escravo em estado transitório. Várias razões levam a esse tipo de escravidão, inclusive dívida não paga que obrigava a pessoa a penhorar a si mesma e, às vezes, toda sua família. No sistema de parentesco 
ovimbundu, caracterizado por dupla descendência (matrilinear e patrilinear), o tio materno pode ser considerado como pai social, e a herança dos bens e a sucessão do cargo passam ao seu sobrinho, filho primogênito da sua irmã, o que ocorre igualmente com as dídivas.

O pika ou dongo, denominação que se refere a um escravo adquirido por guerra, compra, imposto pago a um soberano ou, às vezes, doação. O caso de Ladislau Magyar ilustra um caso de um escravo que nasceu de homem livre, mas, por ter cometido um crime grave (feitiçaria), por ser prisioneiro de guerra, etc, podia ser punido com a escravização. No julgamento tradicional, o culpado por violar as leis da kezila ${ }^{18}$ era vendido, muitas vezes, junto com os seus familiares caso não pagasse o valor estipulado pelo seu crime. Assim, o maior número dos escravos pika resulta de processos de mucano (justiças locais) e chegavam a formar a metade da sociedade ovimbundu. ${ }^{19}$

O papel do dongo abarcava todos os campos principais na sociedade ovimbun$\mathrm{du}$, mas os principais eram as atividades relacionadas à produção agrícola, ao artesanato, ao auxílio ao homem livre na caça, na pesca, etc. Nas transações comerciais entre os homens livres, o escravo era um objeto valoroso. Nos rituais da investidura do potentado, ocorria a morte ritual do escravo especialmente eleito para o efeito chamado ouri-dongo (escravo jovem de bom aspecto físico que se sacrificava durante a cerimônia da investidura do potentado ovimbundu). Outro papel especial do escravo era o de escrivão, pois os potentados os mandavam a Luanda para aprender a ler e a escrever para os servirem como escrivães e intérpretes em suas relações diplomáticas, sobretudo com o governo português.

Além dessa atividade, o pika tinha várias estratégias para melhorar a vida. Casava-se com mulheres livres que podiam dedicar seu tempo à agricultura na terra da família, sem ter que trabalhar para o senhor do marido, mas se se casasse com uma escrava teria que trabalhar para o mesmo senhor. Os filhos eram considerados pela via matrilinear, ou seja, filhos de mulheres livres eram livres. Por isso, os escravos evitaram casar-se com escravas, muitas das quais eram amasias dos seus senhores. Outra estratégia era a fuga. Sobressaía a fuga ${ }^{20}$ 'para sempre' a fim de formar comunidades, processo que se chamava vatira ${ }^{21}$. Porém, havia uma outra fuga, mais frequente, que era uma opção do homem casado e com dificuldades de movimento. Escravas também tentavam melhorar a sua vida. Esvaíam-se até a terra de um proprietário já conhecido, onde esperavam ter melhores condições de vida. Praticavam um ato que se iniciava com o rasgar a roupa do proprietário, causando-lhe danos; depois, comiam um animal. Por fim, declararavan que o pagariam, entregando-se como escravos. Esse tipo de fuga era geralmente denominada tumbica ou simbika.

\section{Palavras finais: a motivação pessoal de Magyar}

O desejo de ser o primeiro em desvendar um enigma, como a origem do rio Nilo, ou encontrar um povo desconhecido, ou uma rede hidrográfica, estimulou muitos exploradores do século XIX. A maioria deles teve apoio e reconhecimento governamen- 
tal ou de uma instituição científica. Magyar faz parte daqueles casos muito raros - tal como, por exemplo, o do sueco Charles J. Andersson $^{22}$ - que realizavam todo o seu trabalho exploratório sozinho, sem apoio institucional. Apesar das propostas reais de financiamento, optou pela independência e autofinanciamento da sua pesquisa. A construção da sua carreira baseava-se na motivação pessoal, que se pode caracterizar como patriótica, bem como por uma inquietude permanente por não ter o reconhecimento legal do pai. Esse fio condutor da sua vida o impedia de aceitar qualquer outra proposta que o promovesse na sua carreira de explorador, mas o afastaria do plano de regresso à Hungria. Suponho que seu estado de órfão de mãe e de filho ilegítimo, assim como o fato de querer pertencer ao lar familiar com os mesmos direitos de outros semi-irmãos mobilizaram suas energias de explorador.

Apesar de limitado em suas finanças, não caiu na tentação das propostas inglesa e portuguesa, congelou-as para o futuro e lançou-se a elaborar o primeiro manuscrito exclusivamente para o leitor húngaro e para a Academia de Ciências da Hungria. Almejou o acolhimento do mundo acadêmico e o reconhecimento legal definitivo do pai. As cartas à família húngara e à Academia de Ciências da Hungria refletem tal estado de espírito, ora repleto de grande entusiasmo, ora de grande decepção. A energia inicial só decresceu quando entendeu que o pai não queria o seu regresso. Sua fidelidade incondicional foi dirigida à Academia, mas já sem grandes forças para elaborar uma obra de fôlego, produzindo apenas artigos, cada vez mais maduros. Legou-nos, porém, uma grande obra, embora ainda muito desconhecida, até mesmo por estudiosos da História da África.

\section{Notas}

1 Nos séculos XX e XXI, o termo ovimbundu é usado como designação étnica de um povo, umbundu é a denominação usada para a língua do povo ovimbundu. Segundo a definição do linguista húngaro István Fodor, da Universidade de Köln, Alemanha, umbundu (Umbunda, Mbundu, Nbundo, Nano, etc.) é uma língua bantu falada nas partes central e Sul de Angola (FODOR, 1983, p. 33) Os estrangeiros confundiam facilmente com o termo Kimbundu, língua da etnia mbundu ou ambundu que vivia na parte norte e nordeste de Angola, dominantemente no hinterland de Luanda. Entretanto, em meados de século XIX a etnia ovimbundu era chamada de kimbunda. Tanto László Magyar como David Livingstone utilizam esta denominação em suas obras. Magyar usa o termo kimbundus para a etnia e kimbunda para a língua. O linguista Fodor contribui com uma explicação mais precisa (FODOR, 1983, p. 35).

2 Em meados do século XIX, no tempo do tráfico ilegal de escravos, os ovimbundu do interior organizavam-se em caravanas (de poucas centenas até vários mil participantes) para realizar viagens comerciais de longa distância que íam do interior até Benguela para trocar produtos africanos (cera, marfim, couro) por produtos europeus (tecidos, aguardente, armas de fogo, pólvora etc.) Segundo Magyar, saíam de Bié para Benguela duas caravanas por ano, com 3.000 membros (Sebestyén, 2012, p. 112). Havia outra rota frequentemente feita do interior de Angola aos impérios de Lunda e Lovar. Na língua umbundo, distingue-se a viagem de caravana do centro de Angola ao litoral (ombaka), da viagem da caravana do soba chamado (omaka). Magyar utiliza o termo kombaka que, na verdade, é uma palavra com preposição. O português Silva Porto, sertanejo e morador em Bié, que conheceu pessoalmente László Magyar, distingue três tipos de caravanas no seu diário. Quipamballa é a caravana que viaja só durante o dia, ombaca é a caravana dos comerciantes bienos e maca é a caravana do soba ovimbundu (BPMP Silva Porto, Ms. 1243:243.) Os participantes da caravana eram dominantemente africanos livres que contrataram carregadores para o transporte de mercadorias e levaram seus 
escravos domésticos para servi-los durante a viagem. A caravana também tinha uma vanguarda e uma retaguarda de defesa, e todos os membros, até os escravos, levaram armas para se defender no caso de ataque de rapina. A estrutura da caravana parecia com a da sociedade ovimbundu, tinha um dirigente que, junto com um conselho, resolvia conflitos internos e externos e tomava decisões sobre as ocorrências durante a viagem. Este grupo de poder representava a caravana nos encontros "diplomáticos" com as autoridades ovimbundu nos sertões, a quem a caravana pagava imposto de passagem.

3 AHU, Lisboa, Conselho Ultramarino 1853. Gambos, 21 de maio de 1853. Carta de László Magyar ao governador de Benguela.

4 "Supondo que a expedição dirigida e composta de oficiais militares de terra e de mar, compreendendo um facultativo médico ou cirurgião, deveriam (...) ser preferidos (...) aqueles, por exemplo, que houvessem completado o curso da escola politécnica; alguns deles deveriam possuir facilidades na práctica dos instrumentos astronómicos para a determinação das latitudes e longitudes, e estas especialmente por meio dos eclipses dos satélites de Júpiter de que o Doutor Lacerda fez sempre uso na sua expedição. A determinção das alturas por meio de barómetro; observações termométricas, barométricas, magnéticas, etc. seriam feitas regularmente. Um naturalista prático, nacional ou estrangeiro, indagaria as produções do país, e faria as colecções que pudesse; e um hábil desenhador completaria o pessoal da expedição. Os itinerários deveriam ser redigidos com a maior atenção, e sem demora seriam postos em forma de mapa, no qual se notariam todas as notícias geográficas interessantes do país percorrido. Uma memória minuciosa compreenderia a descrição do país, dos povos, vocabulários, etc. Antes da partida da expedição seria muito conveniente que cada um dos carregados das observações científicas praticasse por tempo suficiente com os instrumentos de que havia de fazer uso." Mota, 1964:204. Mota, Avelino Teixeira da. O problema da travessia em meados do século XIX. As viagens de Ladislaus Magyar (1849-1859). in A cartografia antiga da África Central e a travessia entre Angola e Moçambique: 1500-1860. Lourenço Marques. Sociedade de Estudos e Moçambique. 1964.

5 Antonio Francisco da Silva Porto (1817-1890) foi um comerciante e explorador português em África, encarnando o mito do colonialismo português. É o autor de Viagens e apontamentos de um portuense em África.
6 Proposta de Ladislau Magyar: "logo que o Governo de Sua Magestade approuver encarregarme da redacção das minhas viagens, onde fiz nove descobertas, com grande gosto o farei por entenso, subdividido em geographia, physi$\mathrm{ca}$, politica e estatistica, e tendo feito as minhas notas astronomicas dos logares descubertos, terei cuidado de forma rum novo mappa geographico do hemisferio do sul de Africa, pois vejo que os mappas mais modernos dos geographos mais acreditados (...). Indicarei ao Governo de Sua Magestade a direcção mais vantajosa, tanto pasa as sciencias como para o commercio, que deve seguir o viajante que atravessar o continente Africano. Como a mais segura, pois grande parte d'estas longitudes foram já trilhadas por mim com o desejo de contribuir quanto me fosse possivel para o bem das sciencias." Gambos, 21 de março de 1853. Carta [de Ladislau Magyar] ao Governador de Benguella Sobre o interior da Africa Austral. Anais do Conselho Ultramarino. Parte não oficial. 22. (1856). p.239. (por diante ACU).

7 Em suas palavras: "Nas vesperas do meu regresso para Benguella, no fim do mez de Maio de 1851, apareceu-me em Chaquilembe, no reino de Lunda, uma carta escripta em arabe, trazida pela minha gente que tinha fora na outra banda do Diambege, de uns mouros com quem lá se encontraram; não sabendo porem o árabe não pude dar solução á dita carta. Estes, depois unindo-se á gente do Sr. Major Coimbra, foram com ella até Quissembo, no reino de Bunda, onde se achava negociando, o dito Sr. Major, com quem segundo consta chegaram até Benguella; tendo tido eu antes de lá chegar uma procedencia de cinco mezes, de maneira que já me achava outra vez no interior em o Quanhama, quando soube por uma carta particular da chegada d'elle. Gambos, 21 de março de 1853, Carta de Magyar ao governador de Benguela, ACU 22. (1856). p. 238.

8 "Peço-te meu querido pai que em nome da nação húngara escreva-me se há na minha pátria (e não duvido que existam) homens entusiastas pela arte e literatura do país e que poderiam apoiar e financiar o meu plano glorioso de atravessar a África Austral do ocidente do oceano Atlântico do até ao oriente Oceano Indico. Escreve-me o nome destes mecenas do país e se é possível pessoalmente informa-os sobre o meu objetivo. Como patriota acho-me obrigado primeiro solicitar apoio do meu país. Estou certo que o receberia do governador geral de Angola, mas assim lamentavelmente a minha obra não seria publicada e lida em húngaro, mas numa língua 
estrangeira." Cha Quilembe, 20 de abril de 1851, Carta de Magyar ao seu pai. (O original húngaro foi traduzido por Éva Sebestyén para português.) Reservados da Biblioteca Academia de Ciências da Hungria, Ms 6328:2v

9 Trata-se do escossês David Livingstone (18131873), autor de Missionary travels and researches in South Africa, publicado em London, Ward, Lock \& CO. Limited, 1857.

10 Arquivo do Ministério dos Negócios Estrangeiros (em adiante MNE), Correspondência expedida à Embaixada de Austria. 132. 7:13.

11 José Rodrigues Coelho do Amaral foi governador anterior em Benguela, engenheiro militar de formação, seguidor e executor fiel da política colonial. Sem relacionamento pessoal com Magyar, aconselhou Sá da Bandeira a considerar a proposta de Magyar e impor, como condição, uma prova sobre seus conhecimentos cartograficos. Amaral ordenou o envio do manuscrito de autoria de Magyar. AHU, DGU, Angola, maço 23.2., doc. 17 de agosto $\mathrm{d} 1857$.

12 Relatório de Antal Reguly e Ferenc Toldy a Comissão da Historia da Academia de Ciências da Hungria. Pest, 21 de dezembro 1857, MTAKK, RAL 50/1858.

13 MAGYAR, László. Dél afrikai Levelei és Naplókivonatai (Cartas e Extractos de diário de África Austral, de Ladislau Magyar (1857) Pest, Eggenberger.

14 Paul Lovejoy, no seu prefácio à edição inglesa de Claude Meillassoux, destaca a complexidade e a exploração do trabalho serviçal em África, analisada por historiadores a partir dos meados do século XX: "The scholarship of the last twenty years has demonstrated that the variety and intensity of servile relationships and methods of oppression that can be equated with the slavery were probably more developed in Africa than anywhere else in the world at any period in history. Furthermore, there were certainly more slaves in Africa in the nineteenth century than there were in the Americas at any time". Cf. Prefácio, in Meillassoux 1999, p. 7.

15 MEILLASSOUX, Claude. The Anthropology of Slavery. The Womb of Iron and Gold. The University of Chicago Press, Chicago 1991.

${ }_{16}$ Em sua época, Magyar nunca foi acusado por autoridades portuguesas de participar do tráfico de escravos. Mas, recentemente, uma pesquisadora alemã de renome, Beatrix Heintze, em Pioneiros Africanos. Caravanas de carregadores na África Centro-Ocidental (entre 1850-1890) Caminho, Lisboa, 2004, p. 229, fez a seguinte afirmação sem nenhuma base documental: "Europeus destemidos, como o plantador de café Joaquim Rodrigues Graça, os comerciantes de escravos e marfim António F. F. da Silva Porto e Ladislau Magyar, bem como os exploradores David Livingstone, Verney Cameron, Hermenegildo Capello, Roberto Ivens, Alexandre A. Da Rocha Serpa Pinto, Paul Pogge, Otto Schütt, Max Buchner, Hermann von Wissmann e Henrique A. Dias de Carvalho, para mencionar apenas os mais importantes, depressa se tornaram conhecidos na Europa graças aos seus relatos e publicações e foram celebrados como pioneiros e "descobridores" do interior africano, o mais tardar após a sua morte." (HEINTZE, 2004, p. 229). A autora usa apenas fontes publicadas.

17 "Segundo o meu cálculo, o número da população da cidade Benguela não ultrapassa a trêss mil e, devido à proibição do tráfico de cativos, tem descrescido significantemente nos últimos anos. A maioria da população é mundombe, poucos mulatos e ainda menos europeus; com excepção de alguns espanhóis e brasileiros, todos são emigrantes portugueses. Ainda moram aqui 1.500 escravos de ambos os sexos." Magyar Ms., 1857: 2.2. Mundombe é nome étnico da população africana que vivia na cidade de Benguela e em seu entorno.

18 Kezila é uma denominação do direito ovimbundu, ou seja, direito consuetudinário ou costumeiro. Sua violação é julgada por um tribunal ovimbundu. A este conjunto processual ovimbundu denomina-se mucano.

19 "Estes povos gananciosos, invejosos, vivem em brigam incessante, por isto consideram frequentemente um ato insignificante, uma palavra ingênua como crime, que viola o seu direito consuetudinário chamada kezila. Não existindo um livro que sirva de código, os mais poderosos interpretam arbitrariamente os atos dos mais fracos. Não existe uma proporção racional entre o crime cometido e a sua punição, que podem ser multas tão pesadas que não é de admirar que uma parte da nação seja vendida como escrava para a outra parte da mesma nação." Magyar Ms, 1857:301.

20 Por exemplo, a "aldeia Tumba encontra-se no meio da planície Bulumbulu, sobre um monte, cercada de árvores incendeira, construída com cerca de 800 casas cobertas de palha. Os seus habitantes refugiaram-se das províncias vizinhas e estabeleceram-se aí. Talvez por causa de um antigo direito consuetudinário, ou pela superstição, eles vivem em paz sob governo patriarcal do seu chefe eleito sem serem molestados pelos vizinhos, tal como os habitantes dos asilos respeitados pelos romanos. Eles reconhecem o potentado 
do Bié pagando-lhe imposto e dando soldados. Vivem de agricultura, comércio e caça, e, segundo a minha experiência, são gentis e hospitaleiros com os forasteiros". Magyar Ms, 1857: 205-206. Incendeira é a tradução portuguesa colonial de mulemba, palavra umbundo. Sua denominação científica é Ficus thonningii Blume. É similar aos embondeiros (designação portuguesa colonial) cujo nome banto é baobab.

21 Em geral, não se usava a palavra kilombo para a comunidade de escravos refugiados. Esta denominação, muitas vezes presente nos trabalhos de Magyar, Silva Porto e outros viajantes, refere-se a acampamento, geralmente improvisado, ao longo das rotas de caravana.

22 Charles John Andersson era um explorador sueco, contemporâneo de László Magyar. Suas explorações desenvolveram-se nas regiões correspondentes a Namíbia e África do Sul. Seus livros principais são: Lake Ngami; or Explorations and Discoveries during Four Years' Wanderings in the Wilds of South Western Africa. $2^{\text {nd }}$ edition. London, Hurst and Blackett publishers, 1856; The Okavango River, a Narrative of Travel, Exploration and Adventure. London, Hurst and Blackett publishers, 1861; e Notes of Travel in South-Western Africa. New York, G.P.Putnam's Sons, 1875.

\section{Abstract}

Among the several travellers visiting Angola in the middle of the 19th century there is a Hungarian explorer, László (Ladislaus) Magyar whose life and work have not been basically studied outside of Hungary. He is an anti-hero who did not let to be influenced by the international scientific recognition and awards. He followed his path as a solitary explorer dealing several relevant topics for his era (domestic slavery, long distance travel of caravans, internal trade, and description of Ovimbundu societies in comparison with semi nomad pastors. This study focuses on the life trajectory of a man with peculiar vision who had courage to create his independent life mixed with adventure and scientific exploration.

Keywords: Ovimbundu. Long distance travel. Hungarian explorer.

\section{Resumen}

Entre los distintos viajeros que visitaron Angola en los meados del siglo XIX existe un explorador húngaro, László Magyar, cuya vida y trabajo son poco estudados fuera da Hungría. Es un antiherói, que seguió la vida de explorador solitário y no se dejaba ser influenciado por instituiciones que prometian reconocimiento científico internacional y premios por su trabajo. En sus trabajos trata temas relevantes a su época como la esclavitud doméstica, el viaje de caravana a larga distancia, el comercio interno, la descripción da las sociedades ovimbundu en comparación con las sociedades de pastores semi-nomades. Este estudio trata de la trayectoria de vida de un hombre con visión peculiar quién tenia el coraje de seguir una vida independiente mezclada de aventura con la exploración científica.

Palabras clave: Ovimbundu.Viaje a larga distancia. Explorador húngaro.

\section{Referências}

ALEXANDRE, Valentim. Portugal e a abolição do tráfico de escravos (1834-51). Análise Social. Lisboa: Instituto de Ciências Sociais, v. XXVI, n. 111 , p. 293-333. 1991. 
CLARENCE-SMITH, Gervase. O III Império Português (1825-1975). Lisboa: Teorema, 1985.

CHILDS, Gladwyn Murray. The Chronology of the Ovimbundu Kingdoms. The Journal of African History, Cambridge: Cambridge University Press. v. 11, n. 2. p. 241-248. 1970.

DELGADO, Ralph. A famosa e histórica Benguela: catálogo dos governadores, 1779 a 1940. Luanda: Governo Geral da Província de Angola, 1940.

DORSEY, George A. The Ocimbanda, or Witch-Doctor of the Ovimbundu of Portuguese Southwest Africa. The Journal of American Folklore, University of Illinois Press. v. 12, n. 46, p. 183-188. 1940.

ECSEDY, Csaba. Magyar László, 1818-1864. Ethnographia, Budapest. v. 53, n. 4, p. 557-564. 1969. In:_. An African Hungarian: László Magyar. Africana Budapest, Budapest. v. 1, p. 10-23. 1984.

FERREIRA, Roquinaldo. Escravidão e revoltas de escravos em Angola (1830-1860). Afro-asia, Salvador. v. 21-22, p. 9-44. 1998-1999.

FODOR, István. Introduction to the history of Umbundu: L. Magyar's records (1859) and later sources. Hamburg: Buske; Budapest: Akadémiai Kiadó, 1983.

HEINTZE, Beatrix. Pioneiros Africanos. Caravanas de carregadores na África Centro-Ocidental (entre 1850 e 1890). Lisboa: Caminho, 2004.

HUNFALVY, János. Magyar László (Emlékbeszéd). Budapesti Szemle, Budapest, v. IV, p. 325-339. 1874.

KRIZSÁN, László. Magyar László. Budapest: Akadémiai Kiadó, 1983.

LIMA, J. J. L. Ensaio sobre a Statistica das Possessões Portuguezas. Livro III, Lisboa: Imprensa Local, 1846.

LIVINGSTONE, David. Missionary Travels and Researches in South Africa. London: John Murray, 1857.
LOPES, Francisco Xavier. O Dombe Grande da Quisamba. Memoria apresentada ao Governador Pedro Alexandrino da Cunha (1847). Annaes do Conselho Ultramarino. Série II. Parte não oficial. Lisboa: Imprensa Nacional, 1858. p. 179-186.

MAGYAR, László. Magyar László délafrikai levelei és naplórészletei. Pest: Eggenberger, 1857.

MAGYAR, Ladislau Amerigo: Carta ao Governador de Benguella, sobre o interior da Africa Austral. Gambos, 21 de Março de 1853. Annaes do Conselho Ultramarino, (1856). $n^{\circ}$. 2. Parte não oficial, série I. Fevereiro de 1854 a Dezembro 1858. Lisboa: Imprensa Nacional, 1856. p. 237-240.

MAGYAR László. Délafrikai utazásai 1849 - 57 években. Pest: Eggenberger, 1859a.

Magyar László's Reisen in Süd-Afrika in den Jahren 1849 bis 1857. Leipzig: Lauffer és Stolp, $1859 b$.

MAGYAR, László. Rövid tudósítás a Moluva vagy Moropuu és Lobál Országokról. Akadémiai Értesítő, Budapest, v. 11, p. 921-941. 1859c.

MAGYAR, Ladislaus. Erforschung von Inner-Afrika. Nachrichten über die von ihm den Jahren 1850, 1851 und 1855 bereisten Lander Moluva, Moropu und Lobal. Petermann's Geographische Mittheilungen, Leipzig, p. 227-237. 1860.

MAGYAR, László. A délafrikai Munda-Evambo, Lungo és Kapota tartományok általános földirati vázlata. Akadémiai Értesítő, Budapest, v. 3, n. 1, p. 254-268. 1862.

MEILLASSOUX, Claude. The Anthropology of Slavery. The Womb of Iron and Gold. Chicago: The University of Chicago Press, 1991.

NOGUEIRA, A. F. A raça negra. Lisboa: Typographia Minerva, 1880.

RODRIGUEZ, H.; ARGUINDEGUY, P. Nómina de Oficiales Navales argentinos (1810-1900). Buenos Aires: Instituto Nacional Browniano, 1998. 
SANTOS, Maria Emília Madeira dos. Viagens e apontamentos de um portuense em África: diário de António Francisco Ferreira da Silva Porto, I. António Francisco Ferreira da Silva Porto. (publ.) Maria Emília Madeira Santos. Coimbra: Biblioteca Geral da Universidade de Coimbra, 1986.

SEBESTYÉN, Éva. Levéltári kutatástörténet: Magyar László. Africana Hungarica, Budapest, v. 1, n. 2, p. 303-327. 1998.

- Mi volt Magyar László halálának oka. Africana Hungarica, Budapest, v. 2, n. 1-2, p. 157-184. 2007.

. Magyar László útinaplója és levelei Afrika belsejéből. Közreadja Sebestyén Éva. Budapest: Balassi Kiadó-MTA Könyvtára, 2008a.

. Kaland és kutatás. Magyar László életrajza. Budapest: ELTE Eötvös Kiadó, Budapest, 2008b.

. Magyar László utazása Del Afrika belsejében 1849-1857 években. Budapest: Balassi Kiadó-MTA Könyvtára, 2012.

SORIANO, Simão José da Luz. Memoria sobre os sertões, e a costa ao Sul de Benguella, na Província de Angola (1846). Annaes Marítimos e Coloniaes. Parte official, 6 série, 3. Lisboa: Imprensa Nacional, 1846. p. 72-100.

SERPA PINTO, Alexandre de. Como eu atravessei a África. 2 vol. Lisboa, Publicações Europa-America, 1998.

TEIXEIRA DA MOTA, A. O Problema da travessia em meados do século dezanove. As viagens de Ladislau Magyar (1849-1859). A Cartografia antiga da África C entral e a travessia entre Angola e Moçambique 1500-1860. Lourenço Marques: Sociedade de Estudos de Moçambique, 1964.

THIRRING, Gusztáv. Magyar László élete és tudományos müködése. Budapest: Kilián, 1937. 